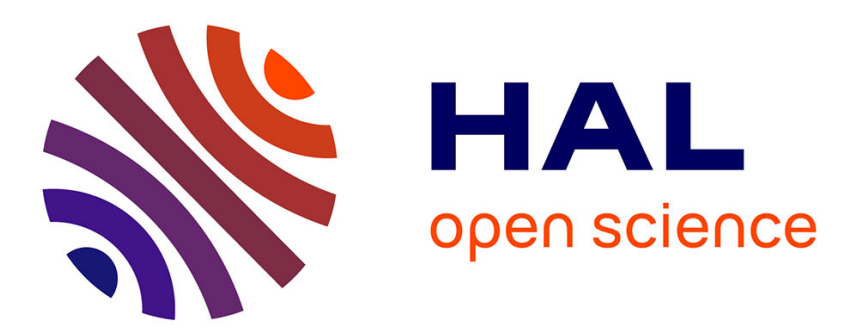

\title{
Molecular tectonics: homochiral 1D and 2D cadmium based coordination networks
}

Patrick Larpent, Abdelaziz Jouaiti, Nathalie Kyritsakas, Mir Wais Hosseini

\section{To cite this version:}

Patrick Larpent, Abdelaziz Jouaiti, Nathalie Kyritsakas, Mir Wais Hosseini. Molecular tectonics: homochiral 1D and 2D cadmium based coordination networks. CrystEngComm, 2019, 21 (15), pp.25342540. 10.1039/c9ce00113a . hal-03011896

\section{HAL Id: hal-03011896 https://hal.science/hal-03011896}

Submitted on 18 Nov 2020

HAL is a multi-disciplinary open access archive for the deposit and dissemination of scientific research documents, whether they are published or not. The documents may come from teaching and research institutions in France or abroad, or from public or private research centers.
L'archive ouverte pluridisciplinaire HAL, est destinée au dépôt et à la diffusion de documents scientifiques de niveau recherche, publiés ou non, émanant des établissements d'enseignement et de recherche français ou étrangers, des laboratoires publics ou privés. 


\title{
Journal Name
}

\section{Molecular tectonics: Homochiral 1D and 2D cadmium based coordination networks}

\author{
Patrick Larpent, Abdelaziz Jouaiti*, Nathalie Kyritsakas and Mir Wais Hosseini*
}

Received 00th January 20xx,

Accepted 00th January 20xx

DOI: $10.1039 / x 0 x \times 00000 x$

\section{www.rsc.org/}

Upon combining enantiomerically pure chiral organic tectons with cadmium nitrate, homochiral 1D and 2D coordination networks are obtained in the crystalline phase. The dimensionality of the latter as well as their packing in the crystal depend on the nature of the chiral side chains of tectons and on the crystallization solvents system used.

\section{Introduction}

Since a few decades, a great deal of attention has been paid to the preparation of Coordination Polymers (CPs), ${ }^{1}$ Metal-Organic Frameworks (MOFs) ${ }^{2}$ or Coordination Newtorks (CN). ${ }^{3}$-The interest in this class of solid state materials results from applications in separation ${ }^{4}$, luminescence ${ }^{5}$, storage 6 and catalysis $^{7}$. For the design and synthesis of such infinite periodic architectures harvested in the crystalline phase, the concepts of molecular tectonics might be applied.3,8 Indeed, upon combinations of properly designed organic tectons with metal cations or complexes (metallatecton), periodic architectures are obtained by self-assembly processes with translation of recognition motifs in one, two or three dimensions leading to 1 , 2- or 3-dimensional architectures. ${ }^{9}$

Nowadays, the use of homochiral coordination networks for enantioselective separation and/or stereospecific transformations ${ }^{10}$ is of prime interest since they may combine advantages of homogeneous and heterogeneous processes. Among different design possibilities to generate homochiral coordination networks, the one using enantio-pure organic tectons is probably the most widespread and reliable. In our previous works, we reported the synthesis of chiral organic tectons and homochiral coordination networks based on $\mathrm{Zn}(\mathrm{II})$, $\mathrm{Hg}(\mathrm{II}), \mathrm{Cu}(\mathrm{II})$ and $\mathrm{Ni}(\mathrm{II})$ cations. $^{11}$ Pursuing our efforts in discovering new homochiral coordination networks, we herein report on the preparation of six new $\mathrm{Cd}(\mathrm{II})$ homochiral networks based on enantiomerically pure tectons 1-3 (Fig. 1). ${ }^{11 a}$ In this contribution, we show how the nature of the appended chiral

\footnotetext{
Molecular Tectonics Laboratory, UMR UDS-CNRS, 7140 \& icFRC, University of Strasbourg, F-67000, Strasbourg, France.E-mail: hosseini@unistra.fr, Fax: +33 368851325; Tel: +33 368851323
}

+ CCDC 1414184-1414189 side chains of the organic tecton and the crystallization media impacts the geometry adopted by the $\mathrm{Cd}^{2+}$ cation, the dimensionality of the coordination networks and the packing of the latter within the crystals.

Tectons 1-3 are derived from 2,5-dibromohydroquinone. They bear two divergently oriented pyridyl units as coordinating sites and two chiral organic moieties (Fig. 1). Tectons $\mathbf{1}(R, R)$ and $\mathbf{2}(S, S)$ are equipped with two hydrophobic chiral alkyl chains of different length and handedness. In contrast, tecton $3(R, R)$ bears two hydrophilic chiral chains due to the presence of $\mathrm{OH}$ groups.

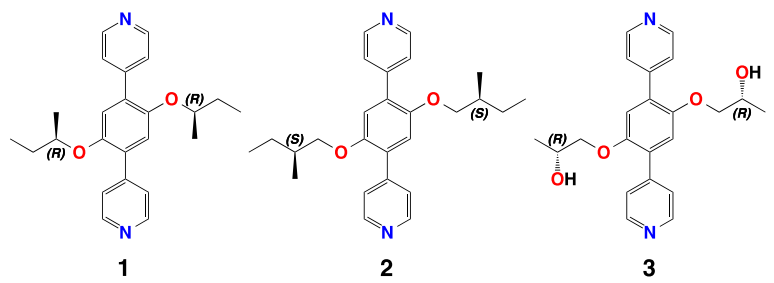

Fig 1: Structure of chiral tectons 1-3 used for the synthesis of $\mathrm{Cd}(\mathrm{II})$ based homochiral coordination networks.

By reacting tectons 1-3 with $\mathrm{Cd}\left(\mathrm{NO}_{3}\right)_{2}$ in two different solvents/non-solvents systems, 2D brick-wall and linear 1D homochiral coordination networks are obtained. Depending on the crystallization media, the geometry adopted by the metallic cation in the solid state and the packing within the crystals are modulated.

\section{Experimental section}

\section{General}

All reagents were purchased from commercial sources and used without further purification. Chiral tectons 1-3 were prepared following published procedures. ${ }^{11 a}$

\section{Characterization techniques}

Elemental analyses were performed on a Thermo Scientific Flash 2000 by the "Service Commun de Microanalyse" of the University of Strasbourg. 


\section{Single crystal X-ray diffraction}

Data were collected on a Bruker APEX8 CCD diffractometer equipped with an Oxford Cryosystem liquid $\mathrm{N}_{2}$ device at $173(2)$ $\mathrm{K}$ using a Molybdenum microfocus sealed tube generator with mirror-monochromated Mo-K $\alpha$ radiation $(\lambda=0.71073 \AA$ ), operating at $50 \mathrm{kV} / 600 \mathrm{~mA}$. For all structures, diffraction data were corrected for absorption. The structures were solved using SHELXS-97 and refined by full matrix least-squares on $\mathrm{F}^{2}$ using SHELXL-97. The hydrogen atoms were introduced at calculated positions and not refined (riding model). ${ }^{12}$

\section{Powder X-ray diffraction}

Powder X-Ray diffraction diagrams were collected on a Bruker D8 diffractometer in reflection mode using monochromatic $\mathrm{Cu}$ $K \alpha$ radiation with a scanning range between 5 and $40^{\circ}$ using a scan step size of $2^{\circ}$. $\mathrm{min}^{-1}$. Air-dried crystals were flattened on a circular sample holder and measured as is.

\section{Luminescence}

Solid state luminescence spectra were acquired on a Perkin Elmer LS55 spectrometer, at ambient temperature under excitation at $350 \mathrm{~nm}$. Crystalline powders were used as synthesized.

\section{Optical microscope}

Optical images were acquired on a Macroscope "MACRO ZOOM ZEISS V16".

\section{Crystallization conditions}

All crystallizations were performed at $c a .25{ }^{\circ} \mathrm{C}$ in a glass via (height $=6.5 \mathrm{~cm}$, diameter $=2 \mathrm{~cm}$ by vapour diffusion of $\mathrm{Et}_{2} \mathrm{O}$ into a solution containing the organic tecton and $\mathrm{Cd}\left(\mathrm{NO}_{3}\right)_{2}$.

1-Cd($\left(\mathrm{NO}_{3}\right)_{2}$. Diffusion of $\mathrm{Et}_{2} \mathrm{O}$ vapours into a $\mathrm{CHCl}_{3} / \mathrm{DMF} / \mathrm{MeOH}$ solution (3.5 mL, 1:1:1.5) of tecton $1(15.0 \mathrm{mg}, 1 \mathrm{eq})$ and $\mathrm{Cd}\left(\mathrm{NO}_{3}\right)_{2}(14.0 \mathrm{mg}$, 1eq) led after few days to the formation of crystalline material which was washed with $\mathrm{Et}_{2} \mathrm{O}$ and dried in air affording $16.6 \mathrm{mg}$ of colourless crystals.

Formula: Cd2C72H84N10O18.CHCl3. Anal. Calc.: C, 50.93; $\mathrm{H}$ 4.98; N, 8.14; found C, 50.75\%; $\mathrm{H}, 5.16 \%, \mathrm{~N}, 9.34 \%$.

2-Cd( $\left(\mathrm{NO}_{3}\right)_{2}$. Diffusion of $\mathrm{Et}_{2} \mathrm{O}$ vapours into a $\mathrm{CHCl}_{3} / \mathrm{DMF} / \mathrm{MeOH}$ solution (3.5 mL, 1:1:1.5) of tecton $2(15.0 \mathrm{mg}, 1 \mathrm{eq})$ and $\mathrm{Cd}\left(\mathrm{NO}_{3}\right)_{2}(11.5 \mathrm{mg}$, 1eq) led after few days to the formation of crystalline material which was washed with $\mathrm{Et}_{2} \mathrm{O}$ and dried in air affording $16.9 \mathrm{mg}$ of colourless crystals.

Formula: $\mathrm{Cd}_{2} \mathrm{C}_{78} \mathrm{H}_{96} \mathrm{~N}_{10} \mathrm{O}_{18}$. Anal. Calc.: C, 55.55\%; $\mathrm{H}, 5.74 \%$; $\mathrm{N}$, 8.31\%; found: C, 55.54\%; $\mathrm{H}, 5.63 \%, \mathrm{~N}, 8.47 \%$.

3-Cd( $\left(\mathrm{NO}_{3}\right)_{2}$-DMF. Diffusion of $\mathrm{Et}_{2} \mathrm{O}$ vapours into a $\mathrm{CHCl}_{3} / \mathrm{DMF} / \mathrm{MeOH}$ solution $(3.5 \mathrm{~mL}, 1: 1: 1.5)$ of tecton 3 (15.0 $\mathrm{mg}, 1 \mathrm{eq})$ and $\mathrm{Cd}\left(\mathrm{NO}_{3}\right)_{2}(12.2 \mathrm{mg}$, 1eq) led after few days to the formation of crystalline material which was washed with $\mathrm{Et}_{2} \mathrm{O}$ and dried in air affording $21.1 \mathrm{mg}$ of yellowish crystals.

Formula: $\mathrm{CdC}_{22} \mathrm{H}_{24} \mathrm{~N}_{4} \mathrm{O}_{10}$.2( $\left.\mathrm{C}_{3} \mathrm{H}_{7} \mathrm{NO}\right)$ Anal. Calc.: C, $44.07 \% ; \mathrm{H}$ $5.02 \%$; N, $11.01 \%$; found C, $43.63 \%$; $\mathrm{H}, 4.90 \%$; N, $10.69 \%$.

1-Cd( $\left(\mathrm{NO}_{3}\right)_{2}$-DMSO. Diffusion of $\mathrm{Et}_{2} \mathrm{O}$ vapours into a $\mathrm{CHCl}_{3} / \mathrm{DMSO} / \mathrm{MeOH}$ solution $(3.5 \mathrm{~mL}, 1: 1: 1.5)$ of tecton 1 (15.0 $\mathrm{mg}, 1 \mathrm{eq})$ and $\mathrm{Cd}\left(\mathrm{NO}_{3}\right)_{2}(14.0 \mathrm{mg}$, 1eq) led after few days to the formation of crystalline material which was washed with $\mathrm{Et}_{2} \mathrm{O}$ and dried in air affording $19.5 \mathrm{mg}$ of colourless crystals.

Formula: $\mathrm{CdC}_{24} \mathrm{H}_{28} \mathrm{~N}_{4} \mathrm{O}_{8} .2\left(\mathrm{C}_{2} \mathrm{H}_{6} \mathrm{OS}\right)$ Anal. Calc.: C, 43.72\%; $\mathrm{H}$, $5.24 \%$; N, 7.28\%; found C, 43.31\%; $\mathrm{H}, 5.23 \% ; \mathrm{N}, 7.19 \%$.

2-Cd( $\left(\mathrm{NO}_{3}\right)_{2}$-DMSO. Diffusion of $\mathrm{Et}_{2} \mathrm{O}$ vapours into a $\mathrm{CHCl}_{3} / \mathrm{DMSO} / \mathrm{MeOH}$ solution $(3.5 \mathrm{~mL}, 1: 1: 1.5)$ of tecton 2 (15.0 $\mathrm{mg}, 1 \mathrm{eq})$ and $\mathrm{Cd}\left(\mathrm{NO}_{3}\right)_{2}(11.5 \mathrm{mg}$, 1eq) led after few days to the formation of crystalline material which was washed with $\mathrm{Et}_{2} \mathrm{O}$ and dried in air affording $22.1 \mathrm{mg}$ of colourless crystals.

Formula: $\mathrm{CdC}_{26} \mathrm{H}_{32} \mathrm{~N}_{4} \mathrm{O}_{8} .2\left(\mathrm{C}_{2} \mathrm{H}_{6} \mathrm{OS}\right)$ Anal. Calc.: C, $45.20 \% ; \mathrm{H}$, $5.56 \%$; N, 7.03\%; found C, 44.94\%; $\mathrm{H}, 5.52 \%$; N, $6.89 \%$.

3-Cd( $\left(\mathrm{NO}_{3}\right)_{2}$-DMSO. Diffusion of $\mathrm{Et}_{2} \mathrm{O}$ vapours into a $\mathrm{CHCl}_{3} / \mathrm{DMSO} / \mathrm{MeOH}$ solution (3.5 mL, 1:1:1.5) of tecton 3 (15.0 $\mathrm{mg}, 1 \mathrm{eq})$ and $\mathrm{Cd}\left(\mathrm{NO}_{3}\right)_{2}(12.2 \mathrm{mg}$, 1eq) led after few days to the formation of crystalline material which was washed with $\mathrm{Et}_{2} \mathrm{O}$ and dried in air affording 20.5 of colourless crystals.

Formula: $\mathrm{CdC}_{22} \mathrm{H}_{24} \mathrm{~N}_{4} \mathrm{O}_{10} .2\left(\mathrm{C}_{2} \mathrm{H}_{6} \mathrm{OS}\right)$ Anal. Calc.: C, $40.39 \% ; \mathrm{H}$, 4.69\%; N, 7.25\%; found C, 39.72\%; H, 4.62\%; N, 7.14\%.

Crystallographic data for 1-Cd( $\left(\mathrm{NO}_{3}\right)_{2} \cdot \mathrm{Cd}_{2} \mathrm{C}_{72} \mathrm{H}_{84} \mathrm{~N}_{10} \mathrm{O}_{18}, 2\left(\mathrm{Et}_{2} \mathrm{O}\right)$, $\mathrm{M}=1750.53$, Triclinic, space group $P 1, \mathrm{a}=12.1508(8) \AA \mathrm{A}, \mathrm{b}=$ 14.2530(8) $\AA, c=14.6096(15), \alpha=109.838(2)^{\circ}, \beta=105.079(2)^{\circ}$, $\gamma=105.393(2)^{\circ}, V=2116.6(3) \AA^{3}, T=173(2) K, Z=1, D_{c}=1.373$ Mg. $\mathrm{m}^{-3}, \mu=0.576 \mathrm{~mm}^{-1}, 149055$ collected reflexions, 21360 $[R$ (int) $=0.0409]$, GooF $=1.006, R 1=0.0354, w R 2=0.0804$ for 1 $>2 \sigma(\mathrm{I})$ and $\mathrm{R} 1=0.0561, \mathrm{wR} 2=0.0887$ for all data, absolute structure parameter $=0.043(14)$.

Crystallographic data for 2- $\mathrm{Cd}\left(\mathrm{NO}_{3}\right)_{2} . \mathrm{Cd}_{2} \mathrm{C}_{78} \mathrm{H}_{96} \mathrm{~N}_{10} \mathrm{O}_{18}, 2\left(\mathrm{Et}_{2} \mathrm{O}\right)$, $\mathrm{M}=1834.69$, Triclinic, space group $P 1, \mathrm{a}=12.4212(4) \AA \mathrm{A}, \mathrm{b}=$ 14.1095(5) $\AA, c=15.4139(8), \alpha=105.001(2)^{\circ}, \beta=101.599(2)^{\circ}, \gamma$ $=111.5660(10)^{\circ}, \mathrm{V}=2290.95(16) \AA^{3}, \mathrm{~T}=173(2) \mathrm{K}, \mathrm{Z}=1, \mathrm{D}_{\mathrm{c}}=$ $1.330 \mathrm{Mg} \cdot \mathrm{m}^{-3}, \mu=0.535 \mathrm{~mm}^{-1}, 54139$ collected reflexions, 20670 $[R$ (int) $=0.0396]$, GooF $=0.994, R 1=0.0522, w R 2=0.1275$ for $\mathrm{I}$ $>2 \sigma(\mathrm{I})$ and $\mathrm{R} 1=0.0724, \mathrm{wR} 2=0.1409$ for all data, absolute structure parameter $=0.041(19)$.

Crystallographic data for 3-Cd( $\left(\mathrm{NO}_{3}\right)_{2}$-DMF. $\mathrm{CdC}_{28} \mathrm{H}_{38} \mathrm{~N}_{6} \mathrm{O}_{12}, \mathrm{M}=$ 763.04, Triclinic, space group $P 1, a=9.58640(10) \AA, b=$ $12.4322(2) \AA, c=15.9217(2), \alpha=69.2050(10)^{\circ}, \beta=72.4780(10)^{\circ}$, $\gamma=73.2950(10)^{\circ}, V=1656.57(4) \AA^{3}, T=173(2) K, Z=2, D_{c}=1.530$ Mg.m ${ }^{-3}, \mu=0.728 \mathrm{~mm}^{-1}, 33438$ collected reflexions, 15756 $[R($ int $)=0.0303]$, GooF $=1.079, R 1=0.0467, w R 2=0.1237$ for $\mathrm{I}$ $>2 \sigma(\mathrm{I})$ and $\mathrm{R} 1=0.0533, \mathrm{wR} 2=0.1304$ for all data, absolute structure parameter $=0.04(2)$.

Crystallographic data for 1-Cd( $\left(\mathrm{NO}_{3}\right)_{2}-\mathrm{DMSO} . \mathrm{CdC}_{28} \mathrm{H}_{40} \mathrm{~N}_{4} \mathrm{O}_{10} \mathrm{~S}_{2}$, $\mathrm{M}=796.16$, Triclinic, space group $P 1, \mathrm{a}=7.4499$ (3) $\AA$, $\mathrm{b}=$ $9.9281(4) \AA, c=12.0888(5), \alpha=88.8060(10)^{\circ}, \beta=72.7240(10)^{\circ}$, $\gamma=84.9260(10)^{\circ}, V=850.43(6) \AA^{3}, T=173(2) K, Z=1, D_{c}=1.502$ Mg. $\mathrm{m}^{-3}, \mu=0.822 \mathrm{~mm}^{-1}, 12095$ collected reflexions, 7152 [R(int) $=0.0144], \mathrm{GooF}=1.091, \mathrm{R} 1=0.0231, \mathrm{WR} 2=0.0548$ for $\mathrm{I}>2 \sigma(\mathrm{I})$ and $\mathrm{R} 1=0.0239, \mathrm{wR} 2=0.0552$ for all data, absolute structure parameter $=0.000(12)$.

Crystallographic data for 2-Cd( $\left(\mathrm{NO}_{3}\right)_{2}$-DMSO. $\mathrm{CdC}_{30} \mathrm{H}_{44} \mathrm{~N}_{4} \mathrm{O}_{10} \mathrm{~S}_{2}$, $\mathrm{M}=797.21$, Triclinic, space group $P 1, \mathrm{a}=7.30280(10) \AA, \mathrm{b}=$ 9.9693(2) $\AA, c=12.9323(2), \alpha=97.3740(10)^{\circ}, \beta=99.6980(10)^{\circ}$, $\gamma=92.8900(10)^{\circ}, V=917.89(3) \AA^{3}, T=173(2) K, Z=1, D_{c}=1.442$ Mg. $\mathrm{m}^{-3}, \mu=0.765 \mathrm{~mm}^{-1}, 21793$ collected reflexions, 8350 [R(int) $=0.0231], \mathrm{GooF}=1.006, \mathrm{R} 1=0.0241, \mathrm{wR} 2=0.0585$ for $\mathrm{I}>2 \sigma(\mathrm{I})$ and $R 1=0.0250, w R 2=0.0591$ for all data, absolute structure parameter $=0.003(10)$. 
Crystallographic data for 3-Cd( $\left(\mathrm{NO}_{3}\right)_{2}$-DMSO. $\mathrm{CdC}_{26} \mathrm{H}_{36} \mathrm{~N}_{4} \mathrm{O}_{12} \mathrm{~S}_{2}$ $M=773.11$, Monoclinic, space group $C 2, a=23.8880(6) \AA, b=$ 14.0385(3) $\AA, c=9.7174(3), \alpha=\gamma=90^{\circ}, \beta=97.9270(10)^{\circ}, V=$ $3227.61(15) \AA^{3}, T=173(2) \mathrm{K}, \mathrm{Z}=4, \mathrm{D}_{\mathrm{c}}=1.591 \mathrm{Mg} \cdot \mathrm{m}^{-3}, \mu=0.872$ $\mathrm{mm}^{-1}, 16659$ collected reflexions, $7258[\mathrm{R}(\mathrm{int})=0.0242]$, GooF $=1.069, \mathrm{R} 1=0.0567, \mathrm{wR} 2=0.1532$ for $\mathrm{I}>2 \sigma(\mathrm{I})$ and $\mathrm{R} 1=0.0675$, $\mathrm{WR2}=0.1634$ for all data, absolute structure parameter $=$ $0.05(7)$.

\section{Results}

\section{Crystallisation solvent system: $\mathrm{CHCl}_{3} / \mathrm{DMF} / \mathrm{MeOH}$}

\section{1-Cd $\left(\mathrm{NO}_{3}\right)_{2}$ and 2- $\mathrm{Cd}\left(\mathrm{NO}_{3}\right)_{2}$}

The combination of tecton $\mathbf{1}$ or $\mathbf{2}$ bearing two hydrophobic chiral substituents and $\mathrm{Cd}\left(\mathrm{NO}_{3}\right)_{2}$ leads to the formation of homochiral 2D brick-wall coordination networks $1-\mathrm{Cd}\left(\mathrm{NO}_{3}\right)_{2}$ and 2-Cd( $\left(\mathrm{NO}_{3}\right)_{2}$. In both cases, the crystals (chiral space group $P 1$ ) are composed of the organic tecton $\mathbf{1}$ or $\mathbf{2}, \mathrm{Cd}^{2+}$ cation, and $\mathrm{NO}_{3}{ }^{-}$anion. In addition, the lattices contain two $\mathrm{Et}_{2} \mathrm{O}$ solvent molecules with no noticeable interaction with the metalorganic network.

In the structures, each $\mathrm{Cd}^{2+}$ cation adopts distorted pentagonal bipyramidal geometry and behaves as a three-connecting Ttype node since four of its seven coordination sites are occupied by two $\mathrm{NO}_{3}$ - chelating units with $\mathrm{O}-\mathrm{Cd}$ distances in the 2.31-2.51 Å range (Fig 2).

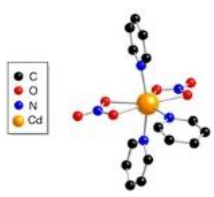

Fig 2. Coordination sphere of $\mathrm{Cd}^{2+}$ in $1-\mathrm{Cd}\left(\mathrm{NO}_{3}\right)_{2}$ and $2-\mathrm{Cd}\left(\mathrm{NO}_{3}\right)_{2}$. Each bis-monodentate chiral tecton $\mathbf{1}$ or $\mathbf{2}$ interconnects two metallic nodes via two $\mathrm{N}-\mathrm{Cd}$ bonds $\left(d_{\mathrm{N}-\mathrm{Cd}}\right.$ in the 2.27-2.36 range) leading, in both cases, to the $2 \mathrm{D}$ brick-wall type network with Cd-Cd distances of ca. $16 \AA$ (Fig 3a and 4a).

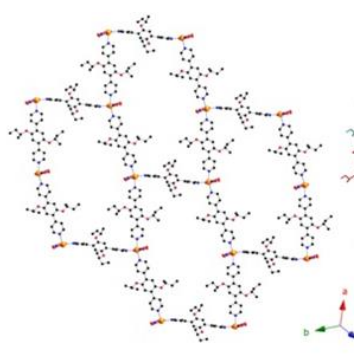

a)

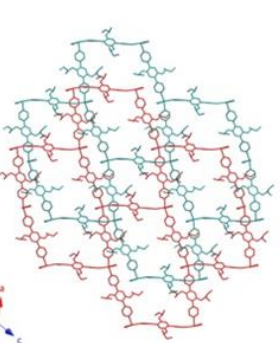

Fig 3. X-Ray structure of $1-\mathrm{Cd}\left(\mathrm{NO}_{3}\right)_{2}$ showing the $2 \mathrm{D}$ brick-wal network (a) and the packing within the crystal (b).

Within the crystals, consecutive 2D network pack in a parallel staggered fashion with the shortest distance between planes of ca. $3.8 \AA$ (Fig $3 \mathrm{~b}$ and Fig $4 \mathrm{~b}$ ). This close-packing mode results in crystals displaying low virtual porosity with calculated solvent accessible voids of $17 \%$ and $18 \%$ (Platon software) for desolvated $1-\mathrm{Cd}\left(\mathrm{NO}_{3}\right)_{2}$ and $2-\mathrm{Cd}\left(\mathrm{NO}_{3}\right)_{2}$ respectively.

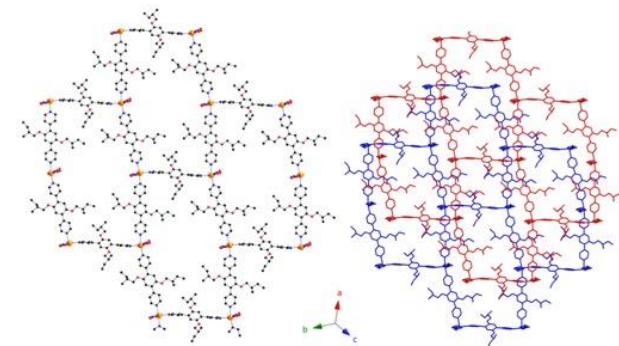

a)

Fig 4. X-Ray structure of $2-\mathrm{Cd}\left(\mathrm{NO}_{3}\right)_{2}$ showing the $2 \mathrm{D}$ brick-wall network (a) and the packing mode within the crystal (b).

The bulk purity of the $1-\mathrm{Cd}\left(\mathrm{NO}_{3}\right)_{2}$ and $2-\mathrm{Cd}\left(\mathrm{NO}_{3}\right)_{2}$ phases was established by PXRD on microcrystalline powders. Owing to the presence of labile solvent molecules within the crystal lattices, air-drying leads to the loss of $\mathrm{Et}_{2} \mathrm{O}$ molecules resulting in crystal lattice changes and therefore in discrepancies between the simulated and recorded PXRD patterns (Fig 5).
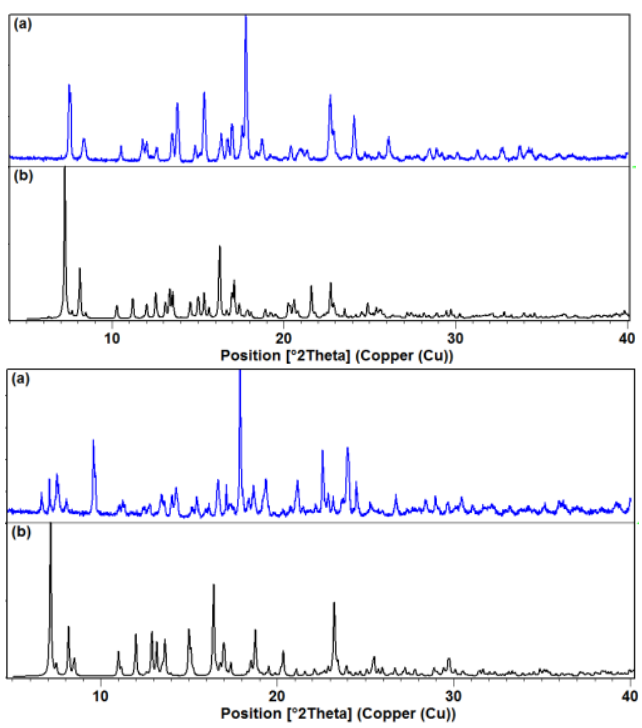

Fig 5. Experimental (a) and simulated (b) PXRD patterns for 1$\mathrm{Cd}\left(\mathrm{NO}_{3}\right)_{2}$ (top) and 2-Cd($\left(\mathrm{NO}_{3}\right)_{2}$ (bottom).

\section{3-Cd( $\left(\mathrm{NO}_{3}\right)_{2}-\mathrm{DMF}$}

The combination of tecton $\mathbf{3}$ bearing two hydrophilic chiral substituents (-OH groups) with $\mathrm{Cd}\left(\mathrm{NO}_{3}\right)_{2}$ under the same crystallisation conditions as for $1-\mathrm{Cd}\left(\mathrm{NO}_{3}\right)_{2}$ and $2-\mathrm{Cd}\left(\mathrm{NO}_{3}\right)_{2}$ leads to the formation of homochiral 1D coordination network 3$\mathrm{Cd}\left(\mathrm{NO}_{3}\right)_{2}-\mathrm{DMF}$.

The crystal (chiral space group $P 1$ ) is composed of the organic tecton 3, $\mathrm{Cd}^{2+}$ cation, $\mathrm{NO}_{3}{ }^{-}$anion and coordinated $\mathrm{DMF}$ molecules. No solvent molecule is present in the interstice of the crystal. Within the crystal, the metallic cation adopts a distorted pentagonal bipyramidal geometry. In that case, in contrast to $1-\mathrm{Cd}\left(\mathrm{NO}_{3}\right)_{2}$ and $2-\mathrm{Cd}\left(\mathrm{NO}_{3}\right)_{2}$ for which the cation behaves as 3-connecting node, a 2-connecting linear node is 
observed with five of the seven coordination sites on $\mathrm{Cd}^{2+}$ cation occupied by two $\mathrm{NO}_{3}{ }^{-}$anions and two DMF molecules (Fig 6).

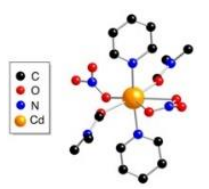

Fig 6. Coordination sphere of $\mathrm{Cd}^{2+}$ in 3-Cd( $\left(\mathrm{NO}_{3}\right)_{2}-\mathrm{DMF}$.

One $\mathrm{NO}_{3}-$ unit acts as a chelate with $\mathrm{O}-\mathrm{Cd}$ bond distances of 2.42 and $2.62 \AA$ and one $\mathrm{NO}_{3}{ }^{-}$anion as a monodentate ligand with $\mathrm{O}$ $\mathrm{Cd}$ of $c a .2 .43 \AA$. Two DMF molecules also coordinate the $\mathrm{Cd}^{2+}$ cation via O-Cd bonds of $c a .2,36 \AA$. The two remaining positions are occupied by two bis-monodentate tectons 3 via $\mathrm{N}-\mathrm{Cd}$ bonds of 2.26 and $2.29 \AA$. The latter interconnect two metallic nodes yielding the $1 \mathrm{D}$ linear network with $\mathrm{Cd}$-Cd distances of $15.92 \AA$ (Fig 7).

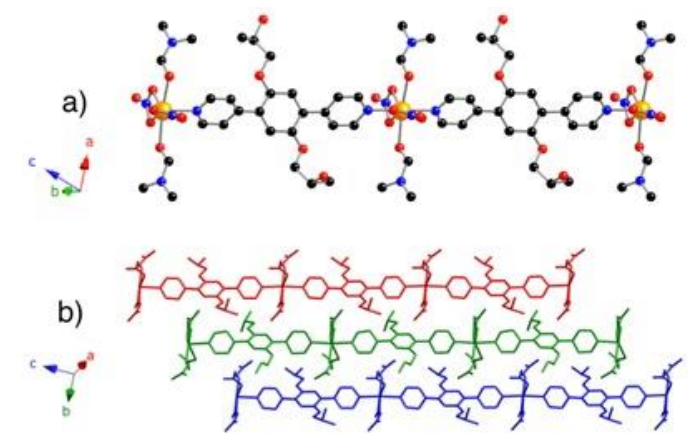

Fig 7. X-Ray structure of $3-\mathrm{Cd}\left(\mathrm{NO}_{3}\right)_{2}-\mathrm{DMF}$ showing the $1 \mathrm{D}$ network (a) and the packing mode within the crystal (b).

Within the crystal, consecutive networks pack in a parallel staggered fashion leading to a dense phase with no specific interactions between the networks and no apparent porosity.

The bulk purity of the 3-Cd( $\left(\mathrm{NO}_{3}\right)_{2}$-DMF phase was confirmed by PXRD on microcrystalline powders which showed a good match between the simulated and observed patterns (Fig 8).

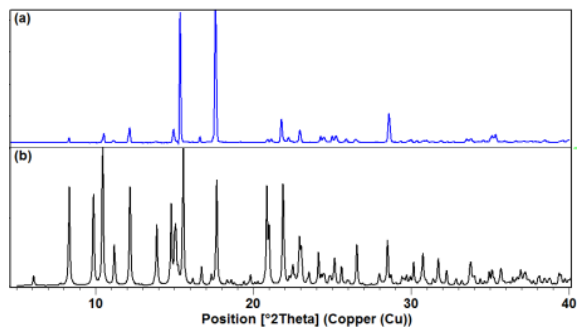

Fig 8. Experimental (a) and simulated (b) PXRD patterns of 3 $\mathrm{Cd}\left(\mathrm{NO}_{3}\right)_{2}$-DMF. Discrepancies in intensities are due to preferential orientations of the microcrystalline powder.

\section{Crystallisation solvent system: $\mathrm{CHCl}_{3} / \mathrm{DMSO} / \mathrm{MeOH}$}

To further investigate the effect of the crystallization media on the formation of crystals based on the coordination networks, crystallisations were performed using DMSO instead of DMF. Upon $\mathrm{Et}_{2} \mathrm{O}$ vapour diffusion into a $\mathrm{CHCl}_{3} / \mathrm{DMSO} / \mathrm{MeOH}$ solution containing one of tectons 1-3 and $\mathrm{Cd}\left(\mathrm{NO}_{3}\right)_{2}$, single crystals were obtained after few days. In all cases, X-ray diffraction on single crystals revealed the formation of homochiral 1D coordination networks. Although the three networks 1- $\mathrm{Cd}\left(\mathrm{NO}_{3}\right)_{2}-\mathrm{DMSO}, 2-$ $\mathrm{Cd}\left(\mathrm{NO}_{3}\right)_{2}$-DMSO and 3-Cd($\left(\mathrm{NO}_{3}\right)_{2}$-DMSO display the same dimensionality and geometry, 3-Cd( $\left(\mathrm{NO}_{3}\right)_{2}$-DMSO exhibits a different packing mode when compared to $1-\mathrm{Cd}\left(\mathrm{NO}_{3}\right)_{2}$-DMSO and $2-\mathrm{Cd}\left(\mathrm{NO}_{3}\right)_{2}-\mathrm{DMSO}$.

\section{1- $\mathrm{Cd}\left(\mathrm{NO}_{3}\right)_{2}-\mathrm{DMSO}$ and 2-Cd(NO$\left.)_{3}\right)_{2}-\mathrm{DMSO}$}

The combination of the tecton 1 or $\mathbf{2}$ with $\mathrm{Cd}\left(\mathrm{NO}_{3}\right)_{2}$ lead to the formation of $1 \mathrm{D}$ linear homochiral coordination networks.

In both cases, the crystals (chiral space group $P 1$ ) are composed of the organic tectons $\mathbf{1}$ or $\mathbf{2}, \mathrm{Cd}^{2+}$ cation, $\mathrm{NO}_{3}{ }^{-}$anion and coordinated DMSO molecules. No guest solvent molecules are present in the crystal lattices.

Within the crystal, the metallic cations adopt a distorted octahedral coordination geometry and behave as a 2connecting node with four of the six coordination sites occupied by $\mathrm{NO}_{3}{ }^{-}$anions and DMSO molecules (Fig 9). The apical positions are occupied by two monodentate $\mathrm{NO}_{3}{ }^{-}$unit through $\mathrm{O}-\mathrm{Cd}$ bonds ( $\mathrm{d}_{\mathrm{o}-\mathrm{cd}}: 2.36-2.38 \AA$ ). Two corners of the square base of the octahedrons, in trans positions, are occupied by two DMSO molecules via O-Cd bonds with O-Cd distance in the 2.28-2.31 range. The two remaining positions are occupied by two organic tectons 1 or 2 via $\mathrm{N}-\mathrm{Cd}$ bond in the 2.28-2.29 Å range.

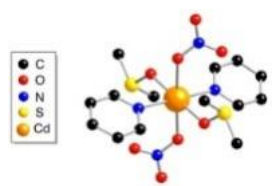

Fig 9. Coordination sphere of $\mathrm{Cd}^{2+}$ in $1-\mathrm{Cd}\left(\mathrm{NO}_{3}\right)_{2}-\mathrm{DMSO}$ and 2 $\mathrm{Cd}\left(\mathrm{NO}_{3}\right)_{2}$-DMSO

The bis-monodentate tectons $\mathbf{1}$ or $\mathbf{2}$ interconnect two metallic nodes leading to the linear 1D networks with $\mathrm{Cd}-\mathrm{Cd}$ distances of ca. $15.97 \AA$ and $15.88 \AA$ for $1-\mathrm{Cd}\left(\mathrm{NO}_{3}\right)_{2}$-DMSO and 2-Cd($\left(\mathrm{NO}_{3}\right)_{2}-$ DMSO respectively (Fig 10a and 11a).

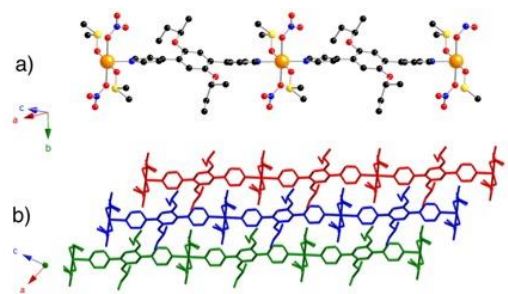

Fig 10. X-ray structure of $1-\mathrm{Cd}\left(\mathrm{NO}_{3}\right)_{2}$-DMSO showing the linear $1 \mathrm{D}$ network (a) and the packing mode within the crystal (b).

Within the crystals, consecutive networks pack in a parallel staggered fashion similarly to $3-\mathrm{Cd}\left(\mathrm{NO}_{3}\right)_{2}$-DMF without specific interaction between the networks (Fig 10b and 11b). The resulting crystals are rather densely packed without any apparent porosity. 


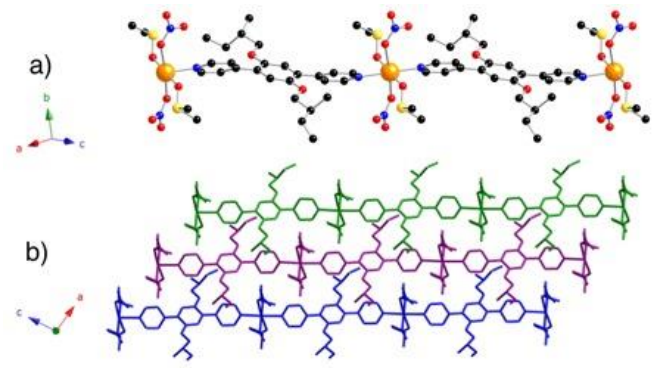

Fig 11. X-ray structure of 2-Cd( $\left(\mathrm{NO}_{3}\right)_{2}$-DMSO showing the linear 1D network (a) and the packing mode within the crystal (b).

The purity of the $1-\mathrm{Cd}\left(\mathrm{NO}_{3}\right)_{2}$-DMSO and 2-Cd(NO$)_{2}$-DMSO phases was established by PXRD on microcrystalline powders which revealed a good match between the simulated and observed patterns (Fig 12 and 13).

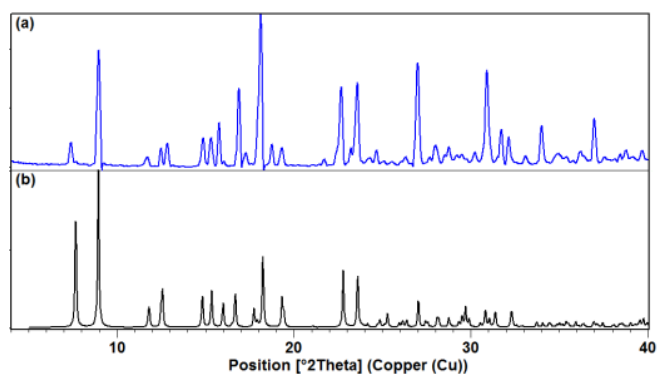

Fig 12. Experimental (a) and simulated (b) PXRD patterns for 1$\mathrm{Cd}\left(\mathrm{NO}_{3}\right)_{2}$-DMSO. Discrepancies in intensities are due to preferential orientations of the microcrystalline powder

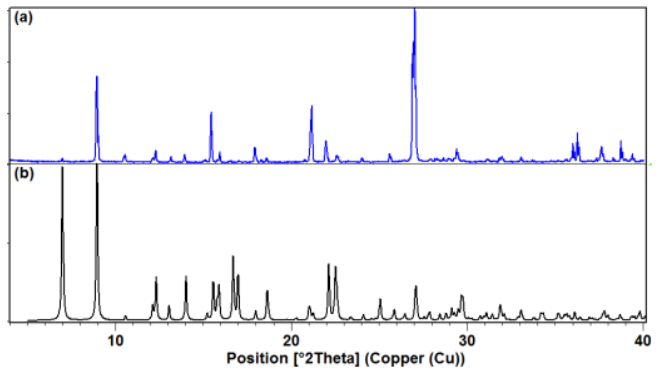

Fig 13. Experimental (a) and simulated (b) PXRD patterns for 2 $\mathrm{Cd}\left(\mathrm{NO}_{3}\right)_{2}$-DMSO. Discrepancies in intensities are due to preferential orientations of the microcrystalline powder.

\section{3- $\mathrm{Cd}\left(\mathrm{NO}_{3}\right)_{2}-\mathrm{DMSO}$}

The combination of tecton 3 with $\mathrm{Cd}\left(\mathrm{NO}_{3}\right)_{2}$ leads to the formation of a 1D linear homochiral coordination network. In contrast with 1-Cd( $\left(\mathrm{NO}_{3}\right)_{2}$-DMSO and 2-Cd( $\left(\mathrm{NO}_{3}\right)_{2}$-DMSO (chiral space group $\mathrm{P} 1$ ), the system crystallizes in the chiral space group C2. The crystal is composed of the chiral organic tecton $\mathbf{3}$, $\mathrm{Cd}^{2+}$ cation, $\mathrm{NO}_{3}{ }^{-}$anion and coordinated DMSO molecules. No unbound solvent molecule is present in the lattice.

The metallic cation adopts the same geometry as in 1- $\mathrm{Cd}\left(\mathrm{NO}_{3}\right)_{2-}$ DMSO and 2-Cd( $\left(\mathrm{NO}_{3}\right)_{2}$-DMSO i.e. distorted $\mathrm{O}_{\mathrm{h}}$. The two apical positions are occupied by two monodentate $\mathrm{NO}_{3}{ }^{-}$units via O-Cd bonds ( $\mathrm{d}_{\mathrm{O}-\mathrm{cd}}$ of 2.39 and $2.45 \AA$ ). Two corners of the square base of the octahedron in trans dispositions are occupied by two DMSO molecules via O-Cd bonds with distances of 2.28 and 2.62
$\AA$. The remaining available coordination sites are occupied by two organic tecton 3 via N-Cd bonds with distances of 2.31 and $2.26 \AA$ A (Fig 14a). Each bis-monodentate tecton 3 interconnects two metallic nodes yielding the $1 \mathrm{D}$ linear network with $\mathrm{Cd}-\mathrm{Cd}$ distances of $15.95 \AA ̊$.

Within the crystal, in the $a b$ plane, consecutive networks pack in a parallel fashion without specific interactions between them (red or blue, Fig 14b). Along the $c$ axis, consecutive networks (red and blue) pack in a twisted fashion with an angle of $c a .61^{\circ}$ between two 1D networks of consecutive layers (red and blue). As a result, rhombus motifs are observed along the $c$ axis (Fig 14b). A dense phase is obtained displaying no porosity.

a)

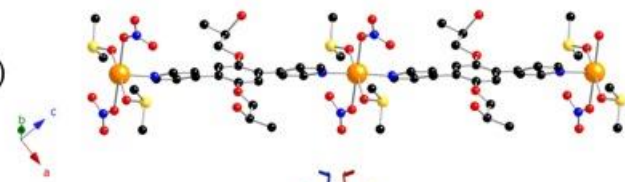

b)

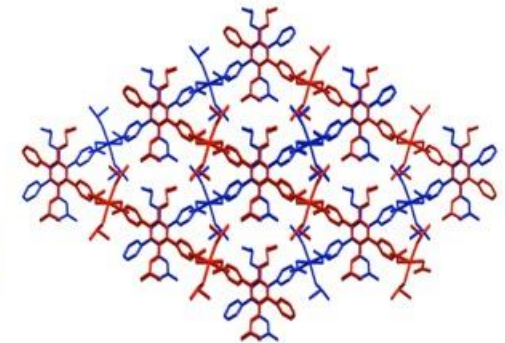

Fig 14. X-ray structure of 3-Cd(NO $\left(\mathrm{NO}_{3}\right)_{2}$ showing the $1 \mathrm{D}$ network (a) and the packing mode within the crystal (b).

The purity of the 3-Cd( $\left(\mathrm{NO}_{3}\right)_{2}$-DMSO phase was confirmed by PXRD on microcrystalline powder which revealed a good match between the simulated and observed patterns (Fig 15).

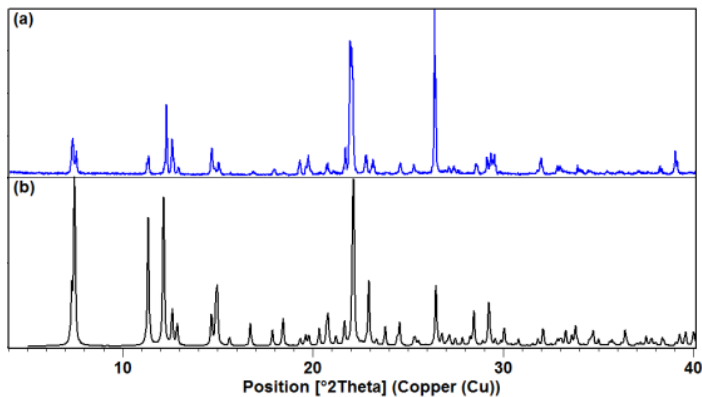

Fig 15. Experimental (a) and simulated (b) PXRD patterns for 3$\mathrm{Cd}\left(\mathrm{NO}_{3}\right)_{2}$-DMSO. Discrepancies in intensities are due to preferential orientations of the microcrystalline powder.

\section{Solid-state luminescence}

All crystals show intense luminescence upon exposure to a lab UV-lamp ( $\lambda=365 \mathrm{~nm}$ ) (Fig 16a). Preliminary investigations around the solid-state emission of the 1D homochiral networks were pursued on micro-crystalline powders. Upon excitation at $350 \mathrm{~nm}$, all powders display broad emission bands between 400 $\mathrm{nm}$ and $500 \mathrm{~nm}$ with maximum intensities centred in the 430$450 \mathrm{~nm}$ region (Fig 16b). Slight shifts in the maximum emissions 
are seen between the different solids which likely result from variations of the chiral side-chains, the coordinated solvents and the packing-mode within the crystals. Further investigations will include determination of quantum yields of luminescence and chiro-optic properties such as Circularly Polarized Luminescent (CPL).

a)
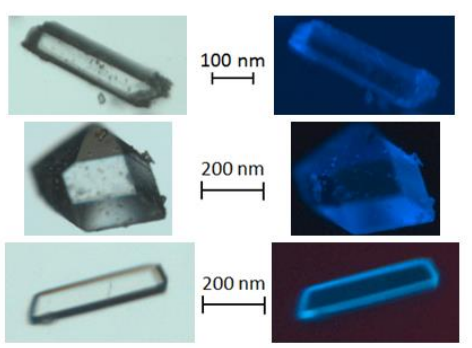

b)

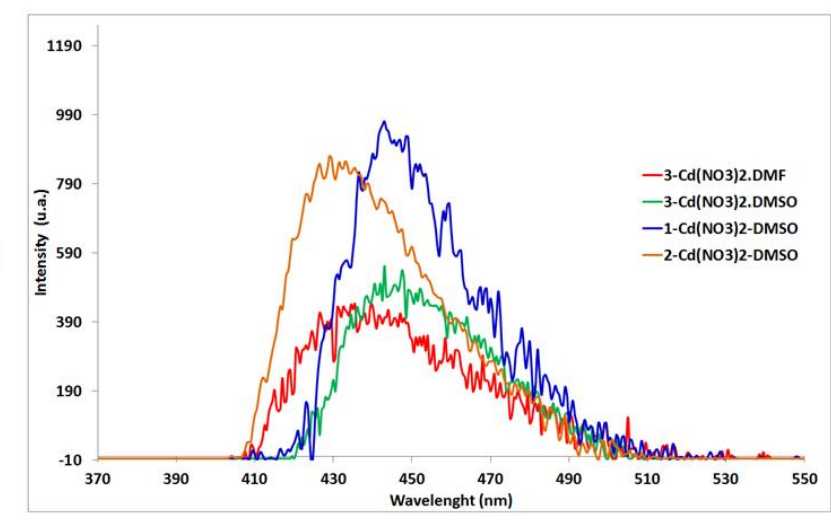

Fig 16. (a) Single crystal optical images of $1-\mathrm{Cd}\left(\mathrm{NO}_{3}\right)_{2}$. DMSO (top), 2-Cd( $\left(\mathrm{NO}_{3}\right)_{2}$.DMSO (middle) and 3-Cd $\left(\mathrm{NO}_{3}\right)_{2}$.DMSO (bottom) under normal light (left) and under $365 \mathrm{~nm}$ UV light (right). (b) Solid-state emission spectra of 1D networked crystalline powders.

\section{Conclusions}

The combinations of chiral tectons $1-3$ with $\mathrm{Cd}\left(\mathrm{NO}_{3}\right)_{2}$ lead to the formation of 2D- and 1D- homochiral coordination networks. Using two distinct crystallisation media, a series of six new coordination networks was obtained and fully characterized in the crystalline phase by both X-ray diffraction on single crystal and by PXRD. The use of chiral tectons 1 and $\mathbf{2}$ bearing two hydrophobic substituents produced 2D brick-wall type coordination networks when combined with $\mathrm{Cd}\left(\mathrm{NO}_{3}\right)_{2}$ in $\mathrm{CHCl}_{3} / \mathrm{DMF} / \mathrm{MeOH}$ ternary mixture. In both cases, the $\mathrm{Cd}^{2+}$ cation adopts a distorted pentagonal bipyramidal geometry and acts as a 3-conecting $\mathrm{T}$-type node leading to the $2 \mathrm{D}$ periodic architectures 1-Cd(NO$\left.)_{3}\right)_{2}$ and 2-Cd( $\left(\mathrm{NO}_{3}\right)_{2}$. In contrast, the use of the chiral tecton $\mathbf{3}$ bearing two hydrophilic chiral substituents yielded under identical crystallization conditions a 1D network 3-Cd( $\left(\mathrm{NO}_{3}\right)_{2}$-DMF. In the latter case, each $\mathrm{Cd}^{2+}$ cation adopts distorted pentagonal bipyramidal geometry and behaves as a linear 2-connecting node.

The use of DMSO instead of DMF yielded exclusively $1 \mathrm{D}$ linear homochiral coordination networks $\left(\mathrm{X}-\mathrm{Cd}\left(\mathrm{NO}_{3}\right)_{2}\right.$-DMSO, $\left.\mathrm{X}=\mathbf{1 - 3}\right)$ regardless of the nature of chiral side chains of the tecton (1-3). In all three cases, the metallic cation adopts a distorted octahedral coordination geometry and acts as a linear connector. Notably, whereas consecutive 1D chains pack in a parallel staggered fashion within the crystals of $1-\mathrm{Cd}\left(\mathrm{NO}_{3}\right)_{2^{-}}$ DMSO and 2-Cd($\left(\mathrm{NO}_{3}\right)_{2}$-DMSO, a different organization is observed for 3-Cd( $\left(\mathrm{NO}_{3}\right)_{2}$-DMSO. Here, sheets of parallelarranged 1D networks ( $a b$ plane) stack in a twisted fashion along the $c$ axis yielding rhombus motifs along this axis.

Although the negligible porosity of all the crystals prevents their use in chiral separation, nevertheless, owing to the strong luminescence of the homochiral crystals observed under UV light, they may be of interest for Circularly Polarized Luminescence (CPL).

We thank the University of Strasbourg, the Institut Universitaire de France, the C.N.R.S., the International centre for Frontier Research in Chemistry (icFRC), the Labex CSC (ANR-10-LABX- 0026 CSC) within the Investissement d'Avenir program ANR-10-IDEX-000202 for financial support.

\section{Conflicts of interest}

There are no conflicts to declare.

\section{Notes and references}

1 (a) B.F. Abrahams, B. F. Hoskins and R. Robson, J. Am. Chem. Soc, 1991, 113, 3606-3607; (b) S. R. Batten and R. Robson, Angew. Chem. Int. Ed., 1998, 37, 1460-1494.

2 H.-C. Zhou, J.R. Long, O. M. Yaghi, Chem. Rev., 2012, 112, 673674.

3 M. W. Hosseini, CrystEngComm, 2004, 6, 318-322

4 (a) J.-R. Li, J. Sculley, H.-C. Zhou, Chem. Rev., 2012, 112, 869-932; (b) B. Chen, S. Xiang, G. Qian, Acc. Chem. Res., 2010, 43, 1115-1124; (c) Z.-Y. Gu, C.-X. Yang, N. Chang, X.-P. Yan, Acc. Chem. Res., 2012, 45, 734-745, (d) H. Li, K. Wang, Y. Sun, C. T. Lollar, J. Li, H-C. Zhou, Materials Today, 2018, 21, 108-121, (e) Z. R. Herm, E. D. Bloch, J. R. Long, Chem. Mater., 2014, 26, 323-338.

5 (a) M. D. Allendorf, C. A. Bauer, R. K. Bhakta, R. J. T. Houk, Chem. Soc. Rev., 2009, 38, 1330-1352, (b) F-Y. Yi, M. Gu, S-C. Wang, J-Q. Zheng, L. Pan, L. Han, Inorg. Chem., 2018, 57, 2654-2662.

6 (a) P. Horcajada, R. Gref, T. Baati, P. K. Allan, G. Maurin, P. Couvreur, G. Férey, R. E. Morris, C. Serre, Chem. Rev., 2012, 112, 1232-1268; (b) Y. Peng, V. Krungleviciute, I. Eryazici, J. T. Hupp, O. K. Farha, T. Yildirim, J. Am. Chem. Soc., 2013, 135, 11887-11894; (c) K. Sumida, D. L. Rogow, J. A. Mason, T. M. McDonald, E. D. Bloch, Z. R. Herm, T.-H. Bae, J. R. Long, Chem. Rev., 2011, 112, 724-781, (d) T. Tian , Z. Zeng, D. Vulpe, M. E. Casco, G. Divitini, P. A. Midgley, J. Silvester-Albero, J-C. Tan, P. Z. Moghadam, D. Fairen-Jimenez, Nature Materials, 2018, 17, 174-179. 
7 (a) C.-D. Wu, W. Lin, Angew. Chem. Int. Ed., 2007, 46, 1075-1078, (b) J. Lee, O. K. Farha, J. Roberts, K. A. Scheidt, S. T. Nguyen, J. T. Hupp, Chem. Soc. Rev., 2009, 38, 1450-1459; (c) L. Ma, C. Abney, W. Lin, Chem. Soc. Rev., 2009, 38, 1248-1256; (d) M. Yoon, R. Srirambalaji, K. Kim, Chem. Rev., 2012, 112, 1196-1231; (e) C. J. Doonan, C. J. Sumby, CrystEngComm, 2017, 19, 4044-4048; (f) Y-Z. Chen, R. Zhang, L. Jiao, H-L. Jiang, Coord. Chem. Rev., 2018, 362, 123.

8 (a) M. Simard, D. Su and J. D. Wuest, J. Am. Chem. Soc., 1991, 113, 4696-4698; (b) S. Mann, Nature, 1993, 365, 499-505; (c) M. W. Hosseini, Acc. Chem. Res., 2005, 38, 313-323.

9 (a) M. W. Hosseini, Chem. Commun., 2005, 5825-5829; (b) H. Akdas, E. Graf, M. W. Hosseini, A. De Cian, J McB. Harrowfield, Chem. Commun., 2000, 2219-2220.

10 (a) Y. Liu, W. Xuan, Y. Cui, Adv. Mat., 2010, 22, 4112-4135; (b) Z.Y. Gu, C.-X. Yang, N. Chang, X.-P. Yan, Acc. Chem. Res., 2012, 45, 734745; (c) B. Kimoon Kim, Minyoung Yoon, and Sunirban Das, Top. Curr. Chem., 2010, 294, 115-153, (d) M. Padmanaban, P. Müller, C.Lieder, K. Gedrich, R. Grünker, V. Bon, I. Senkovska, S. Baumgärtner, S.Opelt, S. Paasch, E. Brunner, F. Glorius, E. Klemm; S. Kaskel, Chem. Commun., 2011, 47, 12089-12091, (e) D. Asnaghi, R. Corso, P. Larpent, I. Bassanetti, A. Jouaiti, N. Kyritsakas, A. Comotti, P. Sozzani, M. W. Hosseini, Chem. Commun., 2017, 53, 5740-5743.

11 (a) P. Larpent, A. Jouaiti, N. Kyritsakas, M. W. Hosseini, Chem. Commun., 2013, 49, 4468-4470; (b) P. Larpent, A. Jouaiti, N. Kyritsakas, M. W. Hosseini, Dalton Trans., 2014, 43, 166-172; (c) P. Larpent, A. Jouaiti, N. Kyritsakas, M. W. Hosseini, Dalton Trans., 2014, 43, 2000-2006.

12 Sheldrick, G. M.: Program for Crystal Structure Solution; University of Göttingen: Göttingen, Germany, 1997.

\section{Abstract:}

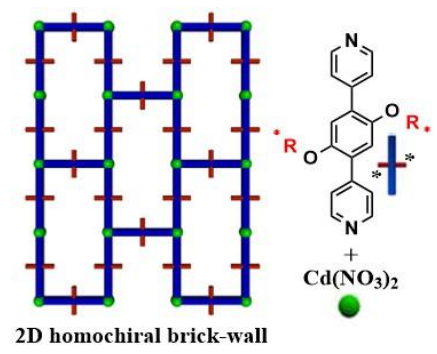

The combination of organic tectons bearing two enantiomerically pure side chains, with $\mathrm{Cd}\left(\mathrm{NO}_{3}\right)_{2}$, leads to a series of six new homochiral coordination networks displaying luminescence in the crystalline state. The dimensionality and crystal packing of the latter are modulated by both the nature of the chiral side chains and the crystallization solvents. 